\title{
Corona exchange dynamics on carbon nanotubes by multiplexed fluo- rescence monitoring
}

\author{
Rebecca L. Pinals, a, Darwin Yang, a, , Alison Lui, ${ }^{a}$ Wendy Cao, ${ }^{\mathrm{b}}$ and Markita P. Landry*a,a,d,e \\ a Department of Chemical and Biomolecular Engineering, University of California, Berkeley, California 94720, United \\ States \\ b Department of Chemistry, University of California, Berkeley, California 94720, United States \\ c Innovative Genomics Institute (IGI), Berkeley, California 94720, United States \\ d California Institute for Quantitative Biosciences, QB3, University of California, Berkeley, California 94720, United \\ States \\ e Chan-Zuckerberg Biohub, San Francisco, California 94158, United States
}

\begin{abstract}
Noncovalent adsorption of DNA on nanoparticles has led to their widespread implementation as gene delivery tools and optical probes. Yet, the behavior and stability of DNA-nanoparticle complexes once applied in biomolecule-rich, in vivo environments remains unpredictable, whereby biocompatibility testing usually occurs in serum. Here, we demonstrate time-resolved measurements of exchange dynamics between solution-phase and adsorbed corona-phase DNA and protein biomolecules on single-walled carbon nanotubes (SWCNTs). We capture real-time binding of fluorophore-labeled biomolecules, utilizing the SWCNT surface as a fluorescence quencher, and apply this corona exchange assay to study protein corona dynamics on ssDNA-SWCNT-based dopamine sensors. We study exchange of two blood proteins, albumin and fibrinogen, adsorbing to and competitively displacing (GT) 6 vs. (GT) 15 ssDNA from ssDNA-SWCNTs. We find that (GT) ${ }_{15}$ binds to SWCNTs with a higher affinity than (GT) 6 and that fibrinogen interacts with ssDNA-SWCNTs more strongly than albumin. Albumin and fibrinogen cause a $52.2 \%$ and $78.2 \%$ attenuation of the dopamine nanosensor response, coinciding with $0.5 \%$ and $3.7 \%$ desorption of (GT) $)_{6}$, respectively. Concurrently, the total surface-adsorbed fibrinogen mass is $168 \%$ greater than that of albumin. Binding profiles are fit to a competitive surface exchange model which recapitulates the experimental observation that fibrinogen has a higher affinity for SWCNTs than albumin, with a fibrinogen on-rate constant 1.61-fold greater and an off-rate constant 0.563 -fold smaller than that of albumin. Our methodology presents a generic route to assess real-time corona exchange on nanoparticles in solution phase, and more broadly motivates testing of nanoparticle-based technologies in blood plasma rather than the more ubiquitously-tested serum conditions.
\end{abstract}

\section{INTRODUCTION}

Adsorption of polymers on single-walled carbon nanotubes (SWCNTs) has enabled developments in molecular sensing, ${ }^{1}$ in vivo imaging, ${ }^{2}$ genetic cargo delivery, ${ }^{3}$ and chirality sorting. ${ }^{4}$ Noncovalent SWCNT functionalization offers a route that preserves the pristine atomic structure, thus retaining the intrinsic near-infrared (nIR) fluorescence of the SWCNTs for the aforementioned applications. However, noncovalent adsorption is an inherently dynamic process, where exchange occurs between molecules in the bulk solution and molecules on the surface, into what is known as the 'corona phase'. In the case of polymers on SWCNTs, the nature, strength, and kinetics of both the polymer binding and unbinding processes are key contributors to the success of polymer-SWCNT based technologies. ${ }^{5}$ Understanding this exchange process is especially critical for intended uses of functionalized SWCNTs to probe biological environments. When a nanoparticle is injected into a biological system, the nanoparticle surface is spontaneously and rapidly coated with proteins to form the 'protein corona'. ${ }^{6}$ In the case of noncovalent polymer-SWCNT complexes, we hypothesize that native biomolecules compete with the original polymer to occupy the nanoparticle surface. Binding of proteins and other biomolecules to the SWCNT can disrupt the intended functionality of the nanoparticle and lead to potentially adverse biocompatibility outcomes. ${ }^{7,8}$ This phenomenon of protein corona formation leads to challenges in translating in vitro sensing or biomolecule delivery platforms to in vivo application. Moreover, the generally accepted method of simulating in vivo biological conditions involves testing nanotechnology performance in blood serum. ${ }^{2,9}$ Yet, the absence of blood coagulation proteins from serum could yield a false outcome in assessing robustness of the nanotechnology and accordingly result in unpredicted failure when applied in vivo.

To clarify how nanoparticle-polymer conjugates behave in biologically-relevant environments, it is pivotal to understand the kinetics describing molecular exchange on nano- 
particle surfaces. Hence, we aim to gain a mechanistic understanding of how SWCNT-based neuromodulator sensors behave in protein-rich milieus. These sensors are based on noncovalent functionalization of (GT) 6 single-stranded DNA (ssDNA) on SWCNTs, resulting in a complex that exhibits ultrasensitive $\Delta \mathrm{F} / \mathrm{F}_{\mathrm{o}}=2400 \%$ and $3500 \%$ fluorescence "turnon" responses in the presence of neuromodulators dopamine and norepinephrine, respectively. ${ }^{10-12}$ However, the drastic enhancement of SWCNT fluorescence experienced upon in vitro exposure to dopamine is attenuated to $\Delta \mathrm{F} / \mathrm{F}_{\mathrm{o}}$ $\approx 20 \%$ once the sensors are applied in brain tissue, ${ }^{12}$ presumably due to protein adsorption and/or disruption of the ssDNA corona phase originally on the SWCNT surface.

Current methods to measure dynamic, noncovalent exchange on nanoparticles exist but are limited in scope. Most research on protein-surface interactions involves characterizing macroscopic surfaces using a series of well-developed techniques that broadly entail an input signal modulated by changing adsorbate mass on the surface as a function of time, including total internal reflection fluorescence microscopy, surface plasmon resonance, biolayer interferometry, and quartz-crystal microbalance with dissipation monitoring. To apply these surface techniques to nanoparticles, the nanoparticles must be surface-immobilized, thus introducing unrealistic topographical constraints that affect ligand exchange kinetics, lead to mass transport limitations, ${ }^{13}$ do not reproduce solution-phase nanosensor responses, ${ }^{14}$ and cause nonselective protein adsorption to any surface left exposed during the sparse SWCNT immobilization process. ${ }^{14}$

An alternative method that permits the study of SWCNTs in solution takes advantage of SWCNT sensitivity to their local dielectric environment ${ }^{15-17}$ by monitoring SWCNT fluorescence intensity changes and solvatochromic shifts upon corona exchange. ${ }^{18,19}$ This technique is applied to study polymer-surfactant exchange kinetics, ${ }^{20-23}$ whereby SWCNTs suspended with surfactant exhibit higher quantum yield and optical transition energy (i.e. blue-shifted spectra) compared to SWCNTs suspended with most biomolecules such as protein or ssDNA. Previous work has successfully applied measurable differences in SWCNT fluorescence spectra to study relative changes in corona surface composition. ${ }^{24,25}$ However, this approach cannot distinguish the exchange of two biomolecules (here, ssDNA to protein), nor can it distinguish between molecular rearrangement vs. molecular desorption from the SWCNT surface. Despite the advantage of undertaking corona exchange studies in the solution phase with this approach, its low sensitivity, non-quantitative nature, and inability to distinguish between adsorbed biomolecules nullifies its potential for monitoring ssDNAprotein exchange.

In this work, we present an assay that overcomes the limitations of previous characterization methods to study corona exchange dynamics between solution-phase and corona-phase biopolymers on SWCNTs, specifically applied to ssDNA and protein. This assay exploits the quenching of fluorophores when in close proximity to the SWCNT surface to monitor ligand binding and unbinding events. ${ }^{26}$ While prior literature has similarly harnessed fluorophore quenching by SWCNTs to study the ssDNA-to-SWCNT binding process, ${ }^{8,18,27}$ far less is known regarding how pre-adsorbed ssDNA and biologically native proteins exchange on the SWCNTs. To our knowledge, this method is unique in enabling real-time monitoring of SWCNT surface exchange between ssDNA and proteins, tracing the fate of all biomolecules involved in the binding exchange. We conduct multiplexed fluorescence tracking of polymer adsorption and desorption events to/from the SWCNT surface. As a case study for this assay, we focus on comparing the sorption behavior of two specific blood proteins, human serum albumin and fibrinogen, chosen because: (i) both are highly abundant in plasma, with albumin as $\sim 55 \%(\mathrm{w} / \mathrm{v})$ of blood plasma, or $35-50 \mathrm{mg} / \mathrm{mL}^{28}$ and fibrinogen as $\sim 4 \%(\mathrm{w} / \mathrm{v})$ of blood plasma, or $1.5-4.5 \mathrm{mg} / \mathrm{mL}^{29}$, (ii) albumin is present in both blood plasma and serum, whereas fibrinogen is a key coagulation protein present in plasma but depleted from serum, and (iii) albumin and fibrinogen are known to be interfacially active proteins prone to surface-adsorption and are implicated in the formation of many other nanoparticle coronas. ${ }^{30-32}$ Binding profiles from the experimental assay in conjunction with a competitive-exchange model are used to extract kinetic parameters for each adsorbent species. Although this study specifically examines competitive adsorption of individual plasma proteins, albumin and fibrinogen, onto (GT) 6 - and (GT) ${ }_{15}$-SWCNTs, the assay is general to any molecules that can be fluorescently labeled and to any nanomaterial surface to which these species may adsorb and display quenched fluorescence. Binding is also validated against the orthogonal and more ubiquitously-used platform monitoring solvatochromic shifting of the nIR SWCNT spectrum as a proxy for SWCNT corona coverage. ${ }^{24,25}$ The work presented herein develops an understanding of the fundamental corona exchange mechanism, contextualizes the nature of the ligand exchange process vs. SWCNT solvatochromic shifting, and provides guidance for testing the performance of SWCNT-based systems in biologically relevant, protein-rich conditions.

\section{RESULTS AND DISCUSSION}

\subsection{Proteins attenuate dopamine sensor response}

Noncovalent modification of single-walled carbon nanotubes (SWCNTs) with single-stranded (GT) 6 DNA imparts nIR fluorescence responsivity to the small molecule neurotransmitter, dopamine. ${ }^{10,11,33}$ Addition of $200 \mu \mathrm{M}$ dopamine to $5 \mu \mathrm{g} / \mathrm{mL}$ solution-phase (GT) ${ }_{6}$-SWCNTs in phosphate buffered saline (PBS) yields an 11.5-fold increase in nanosensor fluorescence at the $1200 \mathrm{~nm}$ SWCNT emission peak (Fig. 1a; see 4.4 Near-infrared fluorescence measurements methods section). Nanosensor response was diminished in the presence of $40 \mu \mathrm{g} / \mathrm{mL}$ human serum albumin (HSA, Fig. 1b) and $40 \mu \mathrm{g} / \mathrm{mL}$ fibrinogen (FBG, Fig. 1c), proteins abundant in intravenous environments. Incubation of $40 \mu \mathrm{g} / \mathrm{mL}$ HSA or FBG with $5 \mu \mathrm{g} / \mathrm{mL}$ (GT) 6 -SWCNTs reduced fluorescence 
a

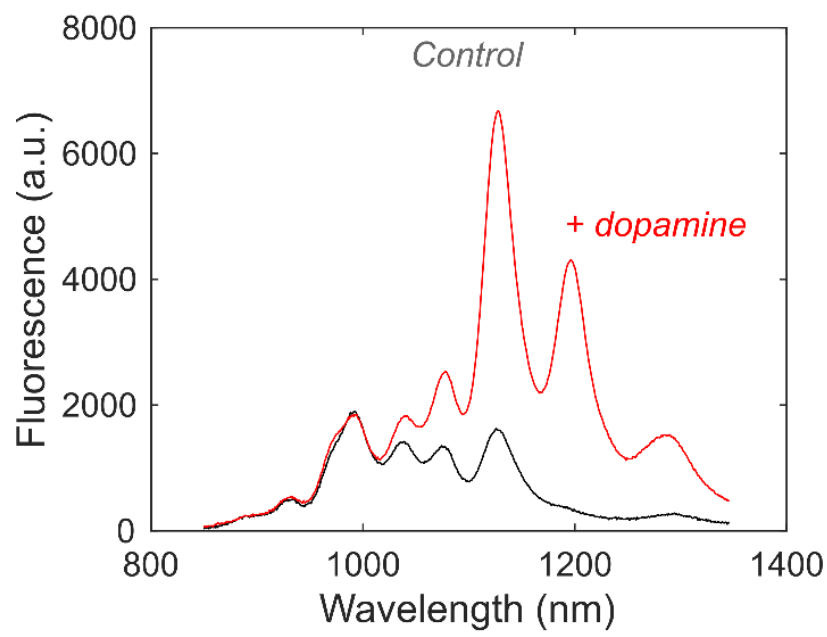

C

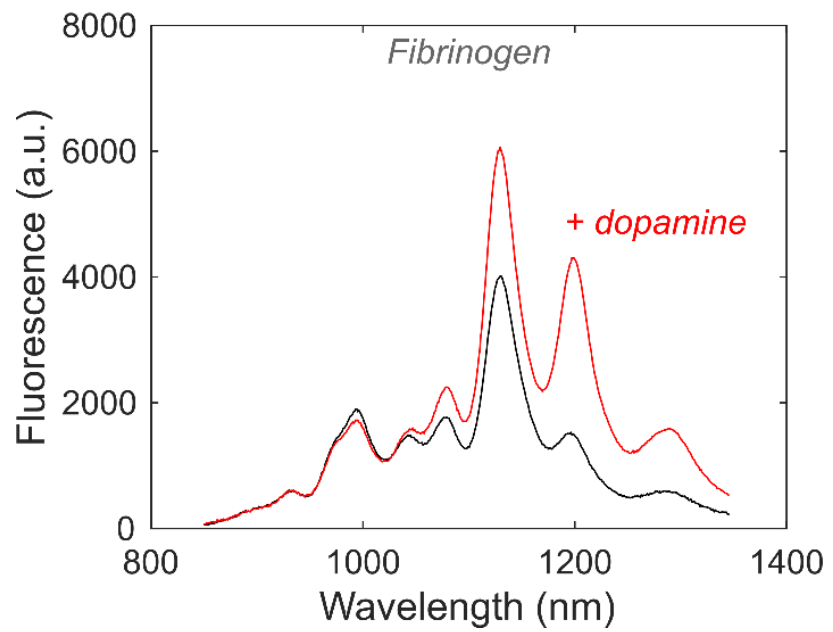

b

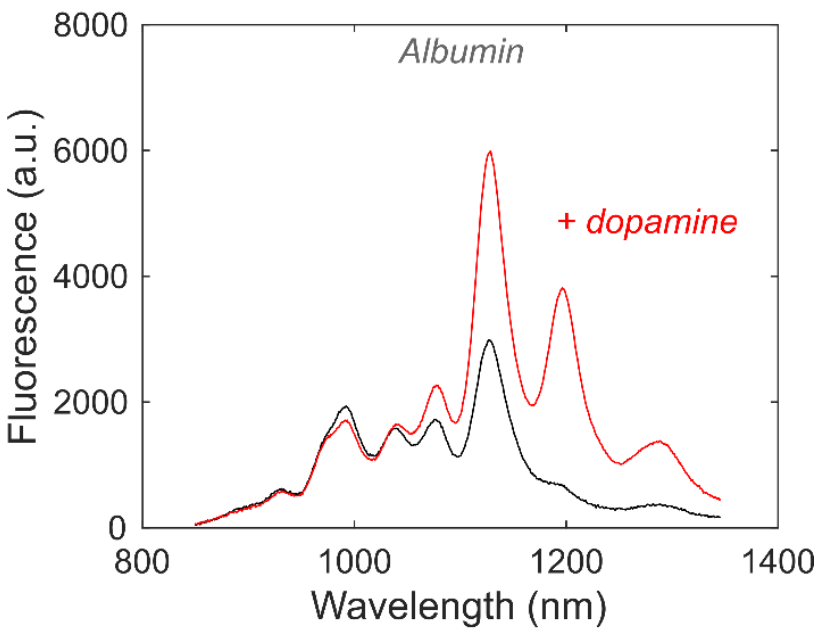

d

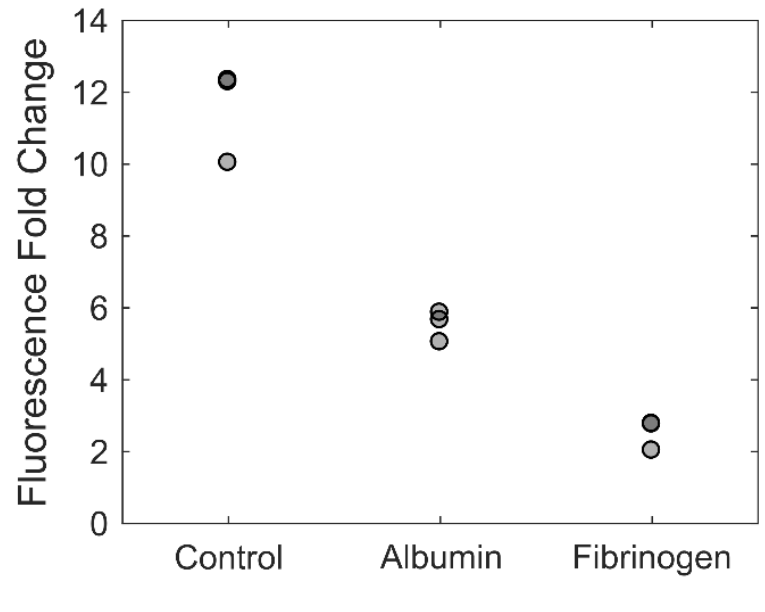

Figure 1. Protein adsorption attenuates (GT) ${ }_{6}$-SWCNT sensor response to dopamine. (a) Near-infrared (nIR) spectra of $5 \mu \mathrm{g} / \mathrm{mL}(\mathrm{GT})_{6}$-SWCNTs before (black) and after (red) addition of $200 \mu \mathrm{M}$ dopamine. (b-c) nIR spectra of $5 \mu \mathrm{g} / \mathrm{mL}(\mathrm{GT})_{6}$ SWCNTs incubated with $40 \mu \mathrm{g} / \mathrm{mL}$ (b) albumin or (c) fibrinogen for 40 minutes before (black) and after (red) addition of 200 $\mu \mathrm{M}$ dopamine. (d) Change in (GT) 6 -SWCNT fluorescence intensity at $1200 \mathrm{~nm}$ peak following 40 minutes incubation in PBS or protein solution at $40 \mu \mathrm{g} / \mathrm{mL}$, then addition of $200 \mu \mathrm{M}$ dopamine $(\mathrm{N}=3)$. Nanosensor excitation was with $721 \mathrm{~nm}$ light.

dopamine response by $52.2 \%$ or $78.2 \%$ after 40 minutes (Fig. 1d), respectively. Protein-induced attenuation of SWCNTs. HSA did not cause any wavelength shifting of the (GT) ${ }_{6}$-SWCNT emission, while FBG exposure led to a redshift of $2.6 \pm 0.6 \mathrm{~nm}$ (mean \pm standard deviation of $\mathrm{N}=3$ sample replicates). Although changes in both the nIR fluorescence intensity and emission wavelength could indicate protein binding, monitoring the SWCNT fluorescence alone does not provide sufficient information to correlate these phenomena.

We first implemented the solvatochromic shift assay to study surfactant-induced fluorescence changes of $5 \mu \mathrm{g} / \mathrm{mL}$ (GT)6-SWCNTs incubated with either $40 \mu \mathrm{g} / \mathrm{mL}$ HSA or FBG for 40 minutes. Displacement of the biopolymer corona phase with surfactant, here $0.5 \%(\mathrm{w} / \mathrm{v})$ sodium dodecylbenzenesulfonate (SDBS), causes a change in local dielectric environment that in turn leads to a blue shift in SWCNT emission wavelength and an increase in SWCNT fluorescence emission intensity. The magnitude of these observed effects is thought to provide insight on the original
SWCNT-corona stability. Interestingly, FBG incubated with (GT) 6 -SWCNTs resulted in both the largest magnitude wavelength shift and largest fold change in fluorescence intensity upon addition of SDBS (Fig. S1). In contrast, HSA incubated with (GT) ${ }_{6}$-SWCNTs did not show a significantly different wavelength shift or intensity fold change compared to the control, (GT) 6 -SWCNTs incubated with only PBS. These results suggest albumin and fibrinogen proteins may have different binding propensities and kinetics to the SWCNT surface. However, this test fails to decouple the interactions between SWCNTs with ssDNA, protein, and then surfactant. To further study the differential attenuation of sensor response by HSA and FBG, and more thoroughly understand the exchange dynamics occurring on the SWCNT surface, we developed a method for studying SWCNT corona composition by multiplexed fluorescence monitoring.

2.2 Multiplexed fluorescence tracking enables realtime monitoring of ligand exchange dynamics 
Our assay leverages fluorophore quenching induced by proximity to the SWCNT surface to measure surface exchange dynamics. Proteins under study were labeled with a FAM fluorophore (ex/em $=494 / 520 \mathrm{~nm}$ ) using NHS ester conjugation to primary amine groups (see 4.2 Fluorophore-labeling of proteins methods section). Singlestranded DNA (ssDNA) were procured with a 3' terminallylabeled Cy5 fluorophore (ex/em = 648/668 nm), enabling spectrally resolved multiplexed tracking of protein and ssDNA. The ssDNA-Cy5 is initially quenched on the SWCNT surface, increasing in fluorescence upon desorption from the SWCNT. Conversely, the FAM-labeled protein exhibits high fluorescence when added in bulk solution, quenching upon adsorption to the SWCNT surface. In this manner, FAM-labeled protein can be injected into ssDNA-Cy5SWCNTs in a well-plate format and fluorescence changes resulting from biomolecule exchange can be read by a fluorescence plate reader (Fig. 2a). We first employed this method to compare the desorption rates of $(\mathrm{GT})_{6}-\mathrm{Cy} 5$ and $(\mathrm{GT})_{15^{-}}$ Cy5 from SWCNTs upon addition of FAM-labeled HSA and FBG. Both proteins promoted dequenching of Cy5, as compared to the addition of PBS control (Fig. 2b-c). Dequenching was due to complete desorption of ssDNA rather than partial desorption of the 3' end, as verified by confirming that the binding profiles of 3'- vs. internally Cy5-labeled ssDNA are similar (Fig. S2). Fibrinogen generated a $3.09 \pm$ 0.07 Cy5 fluorescence fold increase for (GT) 6 -Cy5-SWCNTs vs. a $1.52 \pm 0.04$ Cy5 fluorescence fold increase for (GT) $15^{-}$ Cy5-SWCNTs. This result suggests (GT) 15 is less readily displaced from the SWCNT surface compared to the shorter (GT) 6 construct, a result consistent with the literature. ${ }^{34-36}$

In the same experiment, protein adsorption onto ssDNACy5-SWCNTs was concurrently tracked via fluorescence quenching of the protein-conjugated FAM. Presence of residual FAM fluorophore in the FAM-protein solution was accounted for by quantifying free FAM and subtracting the minimal change in fluorescence due to free FAM-to-SWCNT interaction (Fig. S3, S4, Table S1). Furthermore, the effect of FAM fluorophore labeling on the protein-exchange dynamics was minimal (Fig. S5), in agreement with previous investigations demonstrating that fluorescein-labeling of proteins does not perturb protein adsorption or function, and additionally that fluorescein signals are proportional to the interfacial mass of the tagged species. ${ }^{37-40}$ By tracking the fluorescence modulation resulting from FAM-protein interactions with ssDNA-Cy5-SWCNTs, we found that FAM-FBG exhibited a comparatively larger degree of quenching than FAM-HSA for both ssDNA-SWCNT suspensions (Fig. 2d-e): upon addition of $40 \mu \mathrm{g} / \mathrm{mL}$ FAM-FBG to $5 \mu \mathrm{g} / \mathrm{mL}$ (GT) ${ }_{6}$ SWCNTs (final concentrations), FBG induced a $42.5 \pm 0.9 \%$ decrease in FAM fluorescence vs. a $25.5 \pm 0.9 \%$ HSAinduced decrease in FAM fluorescence. These results consistently suggest two interaction mechanisms of ssDNA and protein with SWCNTs: (i) (GT) ${ }_{15}$ ssDNA binds to SWCNTs with a higher affinity than (GT) 6 SsDNA, thus reducing protein adsorption, and (ii) FBG interacts with ssDNA-SWCNTs more strongly than HSA. The former result agrees with prior work confirming that the rate of ssDNA desorption from SWCNTs decreases with increasing oligo length, ${ }^{41}$ also valid in the presence of competing biomolecules. ${ }^{8}$ As such, our data suggest that FBG protein adsorption leads to more significant ssDNA desorption from SWCNTs, whereas HSA adsorbs less strongly and accordingly causes less ssDNA desorption from SWCNTs. Interestingly, protein adsorption occurs faster than ssDNA desorption. These experimental results motivate kinetic modeling of ssDNA and protein exchange on SWCNT surfaces.

\subsection{Kinetic modeling of ssDNA/protein competitive binding on SWCNT surface}

To quantitatively probe differences in protein affinities for ssDNA-SWCNTs, we fit Cy5 and FAM fluorescence data to a competitive adsorption model and extracted kinetic parameters for ssDNA and proteins. Multiplexed fluorescence tracking was repeated with $5 \mu \mathrm{g} / \mathrm{mL}$ (GT) 6 -Cy5-SWCNTs and concentrations of FAM-HSA and FAM-FBG ranging from 5 to $160 \mu \mathrm{g} / \mathrm{mL}$. Fluorescence values were converted to mass concentration using standard curves for ssDNA-Cy5 and both FAM-conjugated proteins (Fig. S6). A model was developed for the competitive exchange between ssDNA and protein on the SWCNT surface (Equations 1 and 2). In the model, unbound ssDNA (D) and protein (P) adsorb and desorb reversibly to SWCNT surface sites $\left.{ }^{*}\right)$ :

$$
\begin{aligned}
& D+* k_{1} \\
& k_{2} \\
& \rightleftarrows D * \\
& P+* \stackrel{k_{3}}{\rightleftarrows} P * \\
& k_{4}
\end{aligned}
$$

Total concentration of SWCNT surface sites $\left(\left[^{*}\right]_{\mathrm{T}}\right)$ was fixed, given by a site balance (Equation 3 ), where *, $\mathrm{D}^{*}$, and $\mathrm{P}^{*}$ refer to vacant sites, sites occupied by bound ssDNA, and sites occupied by bound protein, respectively:

$$
[*]_{T}=[*]+[D *]+[P *]
$$

Bound ssDNA and bound protein concentrations were calculated by species conservation, where total ssDNA was determined by desorption experiments (see 4.1 Preparation of sSDNA-SWCNT complexes methods section), total protein was the injected protein quantity, and total vacant sites $\left(\left[{ }^{*}\right]_{\mathrm{T}}\right)$ was a fit parameter. Rate constants $\mathrm{k}_{1}, \mathrm{k}_{2}$ for ssDNA binding/unbinding, $\mathrm{k}_{3}, \mathrm{k}_{4}$ for protein binding/unbinding, and the total concentration of binding sites [*]T were computed using a least squares curve fit of Equations S1 and S2 to experimental data (see 4.5 Kinetic model methods section).

Experimental data of FAM-HSA or FAM-FBG added to (GT) 6-Cy5-SWCNTs was fit to this model for each concentration tested (Fig. 3). All mean relative errors comparing fits to experimental data were $<5 \%$ (Table S2). The model recapitulates the experimental observation that FBG has a higher affinity for SWCNTs (Fig. 3d) than HSA (Fig. 3b), where average $\mathrm{k}_{3, \mathrm{FBG}}=1.43 \times 10^{-5}>\mathrm{k}_{3, \mathrm{HSA}}=8.88 \times 10^{-6} \mathrm{~mL}$ $\mu \mathrm{g}^{-1} \mathrm{~s}^{-1}$ (Table 1, with full fit parameter results in Table S2). At the same initial FAM-protein concentration of $40 \mu \mathrm{g} / \mathrm{mL}$ 

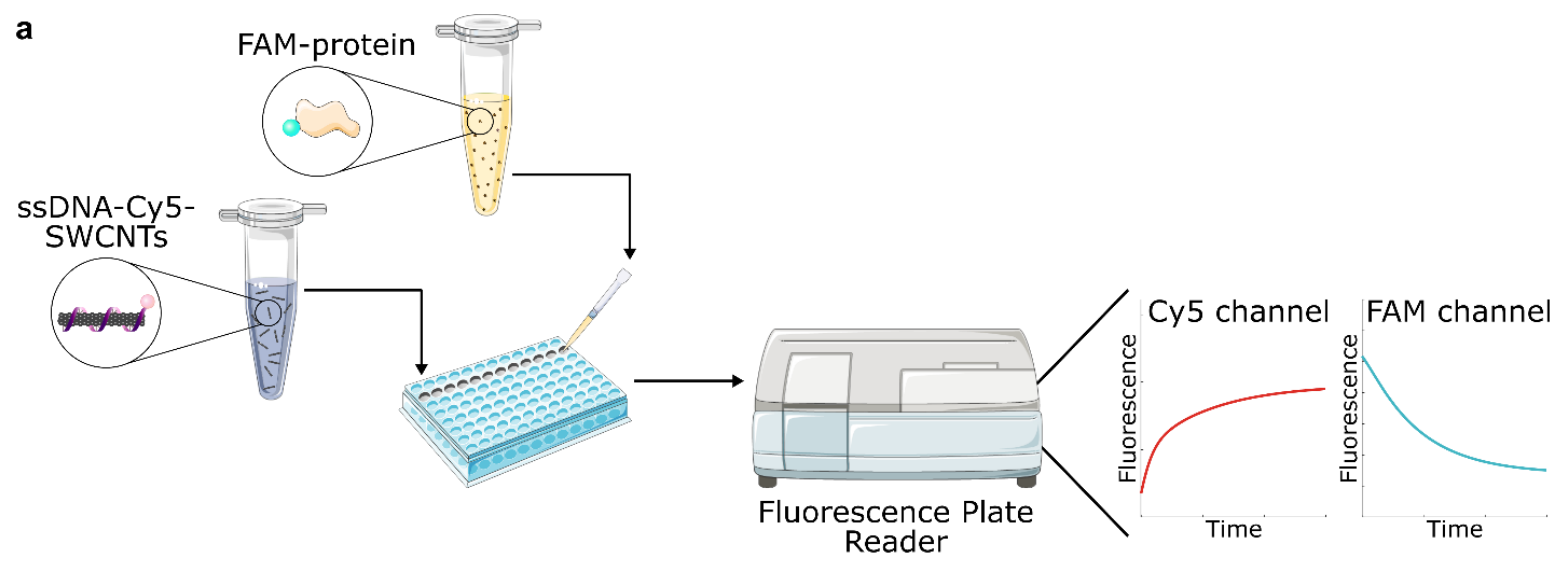

b

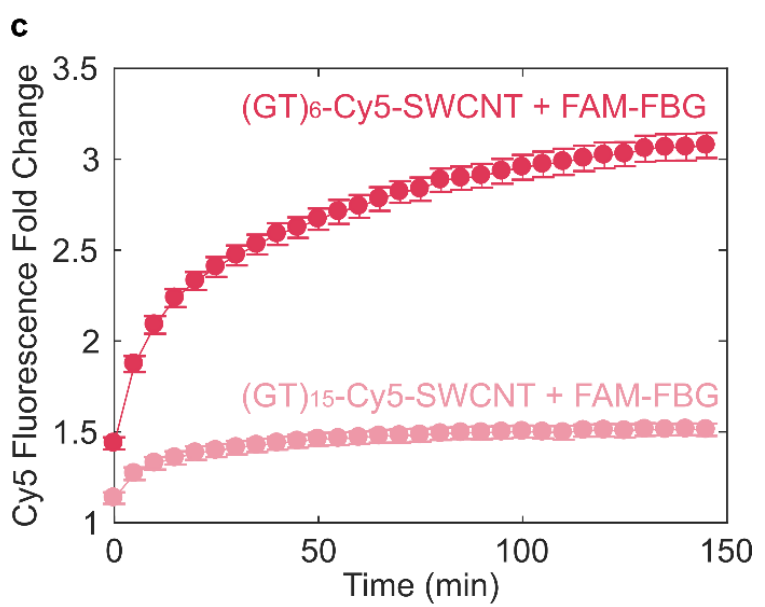

d

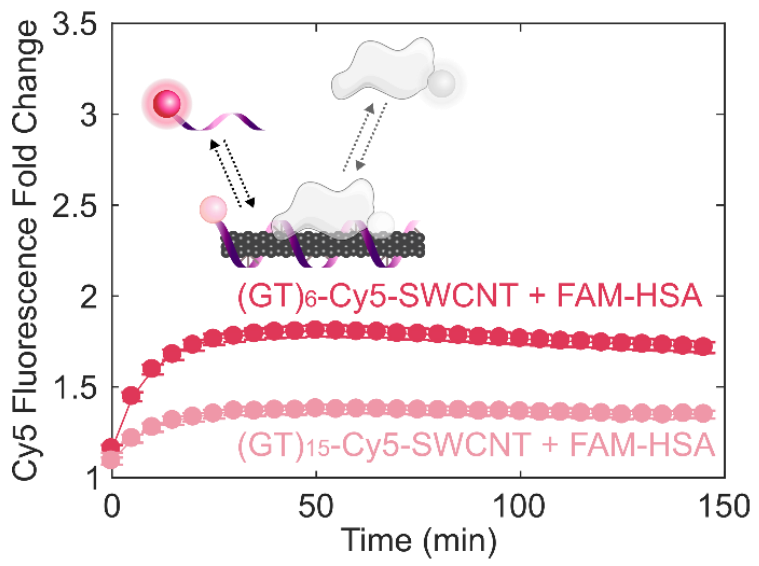

e
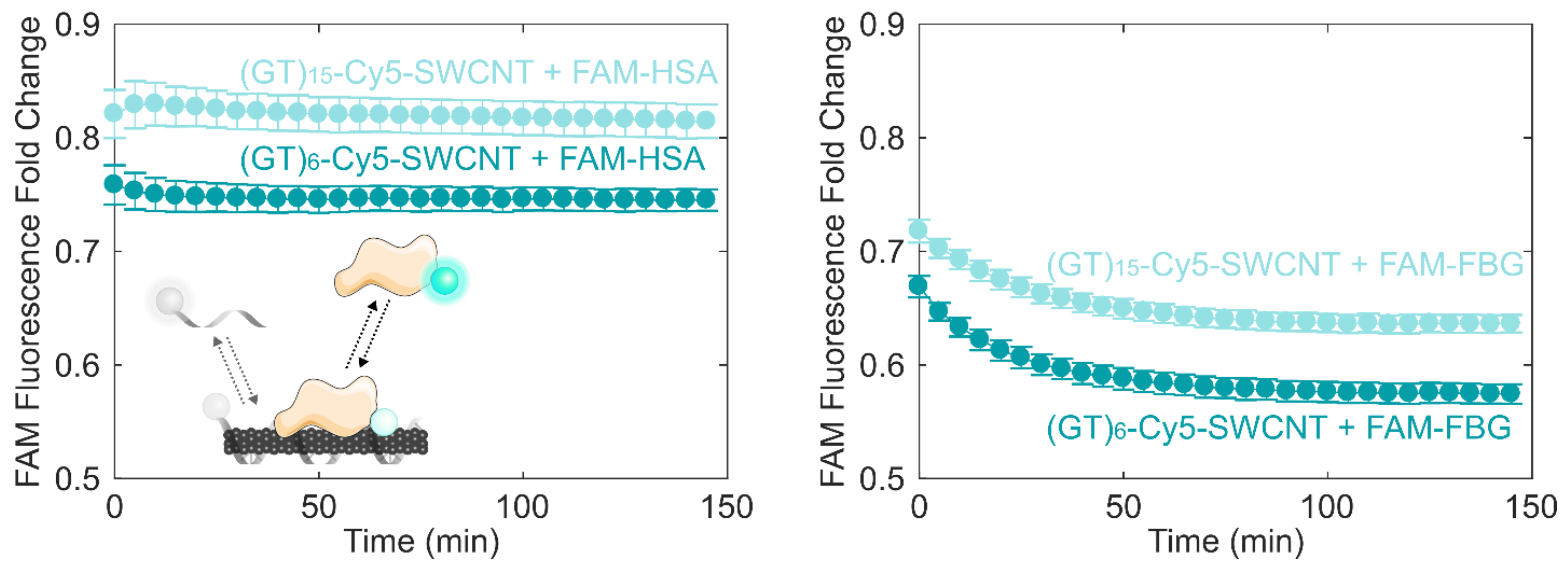

Figure 2. Tracking exchange of fluorophore-labeled ssDNA and protein on SWCNT surfaces demonstrates protein adsorption selectivity and ssDNA length effect. (a) Corona exchange assay workflow. ssDNA-Cy5-SWCNT solution was added to a well-plate, FAM-protein solution was injected, and the ad-/de-sorption processes were monitored in separate color channels of a fluorescence plate reader (see 4.3 Visible fluorescence measurements methods section). Increase in ssDNACy5 fluorescence induced by addition of $40 \mu \mathrm{g} / \mathrm{mL}$ (b) FAM-labeled albumin (FAM-HSA) or (c) FAM-labeled fibrinogen (FAMFBG) to $5 \mu \mathrm{g} / \mathrm{mL}$ ssDNA-Cy5-SWCNT suspended with ssDNA, (GT) 6 or (GT) 15. Decrease in fluorescence of (d) FAM-HSA and (e) FAM-FBG after addition of protein to $(\mathrm{GT})_{6}$ - or $(\mathrm{GT})_{15}$-SWCNT. Error bars represent standard error between experimental replicates $(\mathrm{N}=3)$. 


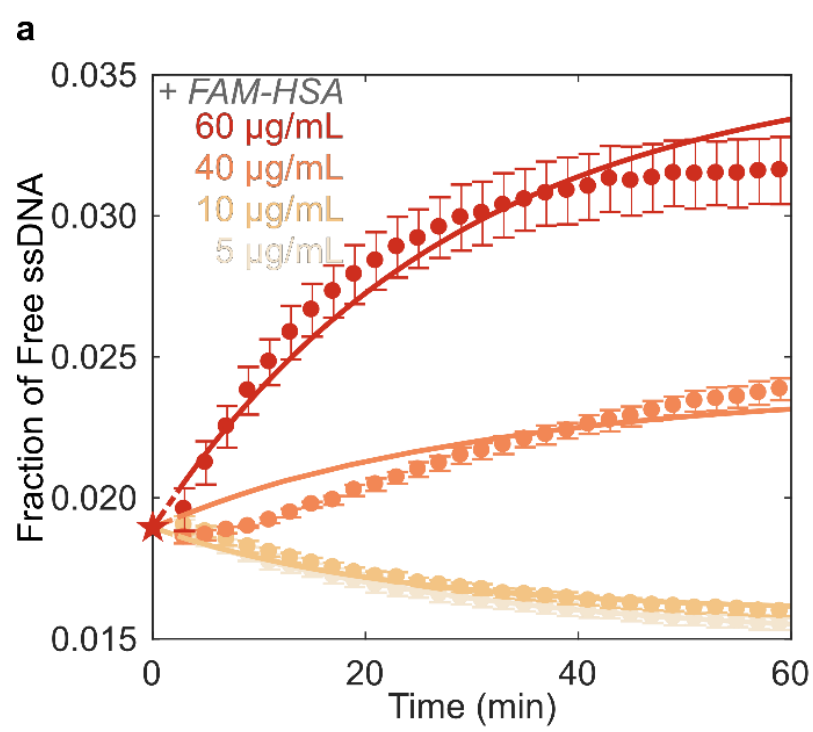

C

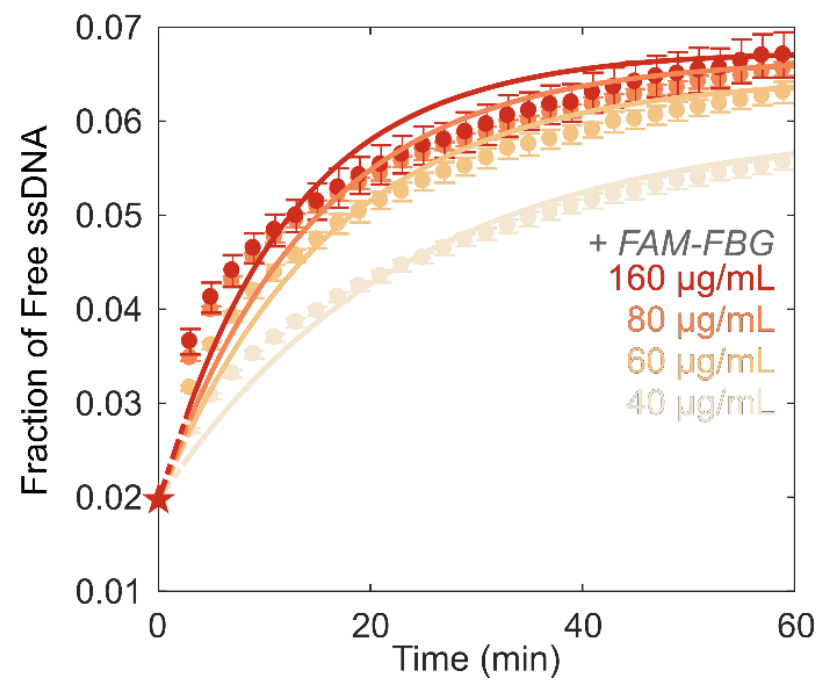

b

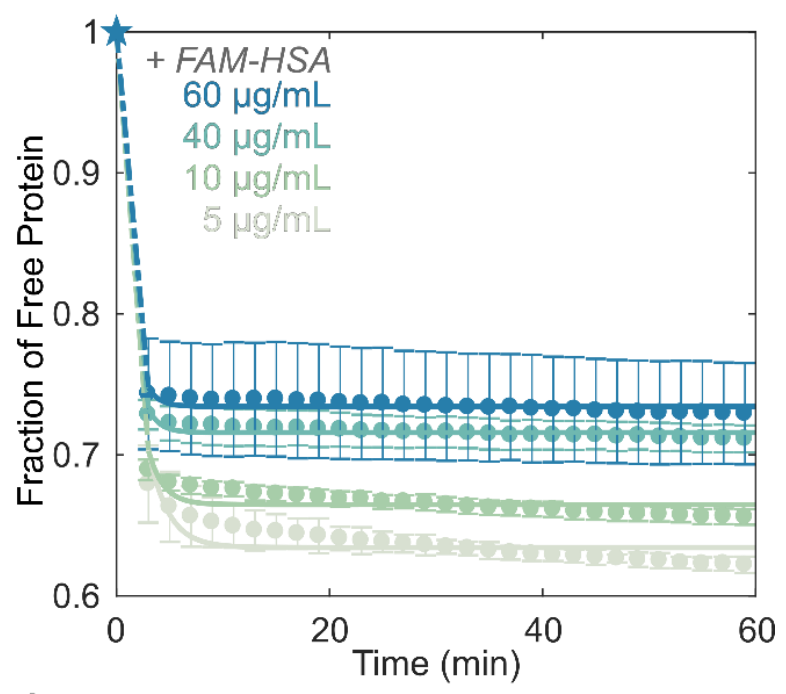

d

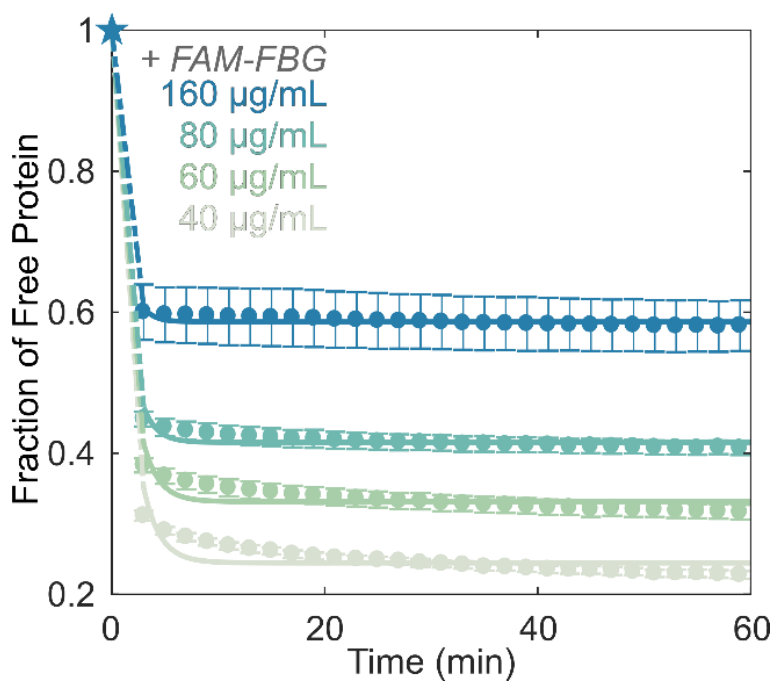

Figure 3. Kinetic model of competitive exchange between sSDNA and protein on SWCNTs fit to fluorescence data to extract rate constants. Fraction of (a) (GT) 6 -Cy5 ssDNA and (b) FAM-labeled albumin (FAM-HSA) protein free in solution for varying concentrations of FAM-HSA injected into $5 \mu \mathrm{g} / \mathrm{mL}$ (GT)6-Cy5-SWCNT solution. Fraction of (c) (GT) 6 -Cy5 ssDNA and (d) FAM-labeled fibrinogen (FAM-FBG) protein free in solution for varying concentrations of FAM-FBG injected into (GT)6-Cy5-SWCNT solution. Star data points represent initial conditions used for solving model differential equations. Error bars represent standard error between experimental replicates $(\mathrm{N}=3)$.

Table 1. Range of kinetic model fit parameters.

\begin{tabular}{|c|c|c|c|c|c|}
\hline Protein & $\begin{array}{c}k_{1} \times 10^{6} \\
\left(m L \mu g^{-1} s^{-1}\right)\end{array}$ & $\begin{array}{c}\mathrm{k}_{2} \times 10^{6} \\
\left(\mathrm{~s}^{-1}\right)\end{array}$ & $\begin{array}{c}k_{3} \times 10^{6} \\
\left(\mathrm{~mL} \mu g^{-1} \mathrm{~s}^{-1}\right)\end{array}$ & $\begin{array}{c}\mathrm{k}_{4} \times 10^{6} \\
\left(\mathrm{~s}^{-1}\right)\end{array}$ & $\begin{array}{c}{\left[{ }^{\star}\right]_{\mathrm{T}}} \\
\left(\mu \mathrm{g} \mathrm{mL}^{-1}\right)\end{array}$ \\
\hline Albumin & $1.10-1.54$ & $8.40-20.7$ & $7.86-9.44$ & $5,850-11,950$ & $365-526$ \\
\hline Fibrinogen & $1.15-2.30$ & $42.7-90.9$ & $11.8-16.9$ & $2,610-9,150$ & $486-620$ \\
\hline
\end{tabular}

added to $5 \mu \mathrm{g} / \mathrm{mL}(\mathrm{GT})_{6}$-Cy5-SWCNTs, FBG adsorbed to a higher fraction of bound protein (0.756) than HSA (0.284) after 1 hour. Addition of FAM-FBG into solution with (GT)6Cy5-SWCNTs led to ssDNA desorption for all tested concentrations of injected FBG (Fig. 3c) but only led to measurable
ssDNA desorption for concentrations $\geq 40 \mu \mathrm{g} / \mathrm{mL}$ of injected HSA (Fig. 3a). Adsorption of ssDNA was observed upon addition of PBS or low concentrations of FAM-HSA ( $\leq$ $20 \mu \mathrm{g} / \mathrm{mL}$ ) to (GT) ${ }_{6}$-Cy5-SWCNTs, indicating an initial excess of unbound ssDNA in bulk solution. Interestingly, for all 
concentrations tested, protein adsorption proceeded significantly faster than ssDNA desorption dynamics, indicating that protein adsorption precedes ssDNA desorption and suggesting that the two phenomena may be decoupled in time. This difference in exchange timescales may be due to the large concentration of total SWCNT surface binding sites (with average fit values of $\left.{ }^{*}\right]_{\mathrm{T}, \mathrm{FBG}}=572 \mu \mathrm{g} \mathrm{mL}{ }^{-1}$ and ${ }^{*}{ }^{*}{ }_{\mathrm{T}, \mathrm{HSA}}$ $=472 \mu \mathrm{g} \mathrm{mL}^{-1}$ ) relative to the total ssDNA and protein concentrations. We hypothesize a low initial ssDNA surface coverage, or large accessible SWCNT surface area, is a likely reason for the difference in exchange timescales. Furthermore, in the case of FBG with (GT) ${ }_{6}$-Cy5-SWCNTs, while amount of adsorbed FBG reaches an apparent steady-state value within $\sim 5$ minutes (Fig. $3 d$ ), ssDNA continues to gradually desorb over time at a rate seemingly independent of injected protein concentration (Fig. 3c). Continued ssDNA desorption may be caused by a surface rearrangement process in the adsorbed FBG layer, ${ }^{42}$ where protein spreading could be responsible for this observed ssDNA displacement over longer timescales. ${ }^{13,38}$ Hydrophobic interactions are posited to be the driving force for protein spreading on the SWCNT surface ${ }^{39}$ and consequently interfacial denaturation is presumed to be the dominant relaxation process, in addition to a smaller contribution from molecular reorientations. ${ }^{37}$

From the kinetic model fitting, the mass of protein adsorbed on the SWCNTs was consistently higher for FBG as compared to HSA for the same initial concentration of 40 $\mu \mathrm{g} / \mathrm{mL}$ FAM-protein with $5 \mu \mathrm{g} / \mathrm{mL}$ (GT) ${ }_{6}$-Cy5-SWCNTs (see 4.5 Kinetic model methods section). Previous studies of differential protein adsorption to hydrophobic surfaces has demonstrated that fibrinogen forms well-packed layers, whereas more weakly adsorbed albumin forms less tightly packed, more mobile adsorption layers. ${ }^{39}$ Accordingly, we hypothesize that the seemingly higher protein surface coverage on the SWCNT points to the more tightly packed, if not multilayer formation, of FBG on the SWCNT surface.

Finally, we note that the dependence of rate constants $\mathrm{k}_{2}$ and $\mathrm{k}_{4}$ on protein concentration indicates that the model is not fully descriptive of the system (Table S2). Some potential shortcomings include that the proposed elementary steps only approximate the true exchange mechanism, or that there are nonidealities present in the protein and/or ssDNA sorption behavior. Nevertheless, the kinetic model captures the key binding profiles and provides a relative comparison between biomolecules binding to the SWCNT surface.

\section{CONCLUSIONS}

Protein adsorption to nanoparticle surfaces is a major hindrance to the successful application of nanotechnologies in vivo. We have shown that incubation of two high-abundance blood plasma proteins, human serum albumin and fibrinogen, with ssDNA-SWCNT dopamine sensors causes significantly different degrees of sensor response attenuation. Developing an understanding of protein-sensor interactions is vital in circumventing this issue and establishing better practices for testing nanotechnologies for in vivo use.
Previously established techniques to evaluate these effects implement surface-immobilized nanoparticles or exploit the intrinsic nIR fluorescence changes of SWCNTs. Yet, these methods do not track the fate of adsorbates and cannot quantify the fraction of free biomolecules in real-time, thus precluding quantitative and temporally-resolved studies of the SWCNT protein corona composition. Though the SDBS-induced solvatochromic shift assay successfully identifies FBG as a protein of interest, this assay provides no mechanistic information on FBG binding, nor can it distinguish between HSA and PBS control responses.

We have addressed these limitations in developing a method to quantitatively probe the kinetics of SWCNT corona exchange between ssDNA and protein adsorbates by monitoring fluorescence quenching of conjugated fluorophores in close proximity to SWCNT surfaces. Concentration curves were fit to a competitive adsorption model to extract kinetic parameters. Our method reveals that reduction of dopamine sensor performance correlates with quantity of adsorbed protein, where fibrinogen adsorbs to ssDNA-SWCNTs $168 \%$ more than albumin at the same concentration, and consequently leads to $26 \%$ more sensor attenuation. We demonstrate significantly greater SWCNT binding affinities for longer repeating ssDNA sequences, and for fibrinogen over albumin. These results bear significance in that albumin is the highest abundance blood protein and is therefore commonly regarded as an important component of the SWCNT corona. However, our results show that lower abundance proteins with higher SWCNT affinities may disproportionately contribute to the SWCNT corona, as has been previously suggested in orthogonal protein corona-nanoparticle studies. ${ }^{43,44}$ Preliminary findings from blood plasma and serum samples normalized to 40 $\mu \mathrm{g} / \mathrm{mL}$ total protein concentration show that plasma and serum both cause significant attenuation of dopamine response in $(\mathrm{GT})_{6}$-Cy5-SWCNTs, with $81.0 \pm 0.9 \%$ and $80.7 \pm$ $1.4 \%$ reduction in response, respectively (Fig S7a). However, plasma-which contains fibrinogen - caused a higher degree of ssDNA desorption, with plasma inducing a $1.64 \pm$ 0.01 fold increase in (GT) 6 -Cy5 fluorescence vs. a $1.39 \pm 0.03$ fold increase by serum (Fig S7b). Our results motivate the necessity to test SWCNT-based and other nanobiotechnologies in more representative bio-environments, i.e. blood plasma rather than serum.

Furthermore, the method presented herein enables the study of protein corona formation dynamics, with standard laboratory equipment, under varying solution conditions (e.g. ionic strength and $\mathrm{pH}$ ) with multiple biomolecular entities. This in turn will facilitate more thorough deconvolution of factors driving protein corona formation and accordingly inform design principles for nanotechnologies resistant to protein corona-based biofouling and performance attenuation. Careful selection of fluorophores may enable further multiplexing, allowing tracking of more than two distinct molecular species simultaneously. Rationally designed labeling methodologies such as FRET may also enable the study of more complex interactions such as protein denaturation on the SWCNT surface. In summary, the corona exchange assay we have developed will serve to en- 
bioRxiv preprint doi: https://doi.org/10.1101/761296; this version posted September 10, 2019. The copyright holder for this preprint (which was not certified by peer review) is the author/funder. All rights reserved. No reuse allowed without permission.

hance our still deficient understanding of how noncovalently bound polymers exchange on nanoparticle surfaces and, accordingly, enable the design and testing of nanobiotechnologies towards effective implementation in vivo.

\section{MATERIALS AND METHODS}

\subsection{Preparation of ssDNA-SWCNT complexes}

Single-stranded DNA with single-walled carbon nanotube (ssDNA-SWCNT) suspensions were prepared by combining $0.2 \mathrm{mg}$ of mixed-chirality SWCNTs (small diameter $\mathrm{HiPCO}^{\mathrm{TM}}$ SWCNTs, NanoIntegris) and $20 \mu \mathrm{M}$ of ssDNA (custom ssDNA oligos with standard desalting, Integrated DNA Technologies, Inc.) in $1 \mathrm{~mL}$ of $0.01 \mathrm{M}$ phosphate-buffered saline (PBS). Solutions were probe-tip sonicated for 10 minutes in an ice bath $(3 \mathrm{~mm}$ probe tip set at $50 \%$ amplitude, 5-6 W, Cole-Parmer Ultrasonic Processor). Samples were centrifuged to pellet insoluble SWCNT bundles and contaminants (16,100 cfg for 30 minutes). Supernatant containing the product was collected. ssDNA-SWCNT solutions were stored at $4^{\circ} \mathrm{C}$ until use. ssDNA-SWCNT concentration was determined via sample absorbance at $910 \mathrm{~nm}$ and the corresponding extinction coefficient $\varepsilon_{910 \mathrm{~nm}}=0.02554 \mathrm{~mL}$ $\mu \mathrm{g}^{-1} \mathrm{~cm}^{-1}{ }^{-15}$ ssDNA-SWCNTs were diluted to a working concentration of $10 \mu \mathrm{g} / \mathrm{mL}$ in $0.1 \mathrm{M}$ PBS.

Cyanine 5 (Cy5) was chosen as the ssDNA fluorophore label, with excitation maximum at $648 \mathrm{~nm}$ and emission maximum at $668 \mathrm{~nm}$. The same suspension protocol was employed for preparation of fluorophore-labeled ssDNASWCNT complexes, using ssDNA-Cy5 (3' or internally-labeled Cy5-labeled custom ssDNA oligos with HPLC purification, Integrated DNA Technologies, Inc.) in place of unlabeled ssDNA. Internally labeled ssDNA-Cy5 includes Cy5 conjugated to the thymine at nucleotide position 6 (GTGTGT/iCy5/GTGTGT).

Total ssDNA adsorbed to SWCNTs was determined by a heat/surfactant elution process. This molar ratio of ssDNA:SWCNT was required to calculate the fraction of free vs. bound ssDNA throughout the exchange process. Optimized elution conditions were achieved with salt and surfactant in the combination of $0.1 \mathrm{M} \mathrm{PBS} / 0.1 \%$ (m/v) sodium dodecylbenzenesulfonate (SDBS), in agreement with prior literature demonstrating that SDBS disperses SWCNTs most effectively 18,46 and without chirality bias. ${ }^{47}$ Freshly prepared ssDNA-Cy5-SWCNTs were diluted to a final concentration of $5 \mu \mathrm{g} / \mathrm{mL}$ in elution buffer, with a final volume of $150 \mu \mathrm{L}$ in a PCR tube. Samples were heated at $95^{\circ} \mathrm{C}$ for 1 hour in a PCR thermocycler, transferred to a clean test-tube, and centrifuged $(16,100 \mathrm{cfg}$ for 30 minutes) to pellet insoluble SWCNT bundles. $120 \mu \mathrm{L}$ of supernatant containing the eluted ssDNA-Cy5 was collected. Fluorescence in the Cy5 channel was measured (see 4.3 Visible fluorescence measurements methods section) and compared to a standard curve of known ssDNA-Cy5 concentrations (ranging $0.01-1 \mu \mathrm{M}$ ) to correlate the Cy5 fluorescence measurement to ssDNA eluted concentration. This resulted in a mole ratio of $364.20 \pm 2.08$ (GT) $6:$ SWCNT and $139.96 \pm 6.67$ (GT) ${ }_{15}$ :SWCNT (both $\mathrm{N}=8$ ), in relative agreement with previous literature for $(6,5)$ single chirality SWCNTs. ${ }^{48}$

\subsection{Fluorophore-labeling of proteins}

$\mathrm{N}$-Hydroxysuccinimide (NHS) ester chemistry was used to label proteins via conjugation to primary amine groups. Fluorescein (FAM) was chosen as the protein fluorophore label, with excitation maximum at $494 \mathrm{~nm}$ and emission maximum at $520 \mathrm{~nm}$ (FAM NHS ester 6-isomer, Lumiprobe). Lyophilized proteins were purchased: human serum albumin (HSA; from human plasma, $\leq 0.02 \%$ Fatty acids, Lot \#SLBZ2785, Millipore Sigma) and fibrinogen (FBG;

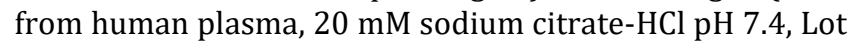
\#3169957, Millipore Sigma). FAM-proteins were prepared with $10 \mathrm{mg}$ of protein reconstituted in $900 \mu \mathrm{L}$ of $0.1 \mathrm{M}$ PBS and 8-fold molar excess of FAM NHS ester solubilized in 100 $\mu \mathrm{L}$ DMSO. Solutions were combined, covered in foil, and incubated on a test-tube rotator for 4 hours. FAM-protein conjugates were twice purified to remove free FAM $\left(\mathrm{Zeba}^{\mathrm{TM}} 2\right.$ mL spin desalting columns with $40 \mathrm{kDa}$ MWCO, Thermo Fisher Scientific) by washing with 0.1 M PBS three times (1,000 cfg for 2 minutes), centrifuging with sample $(1,000$ cfg for 3 minutes), and retaining sample in flow-through solution (repeating all steps twice with a new spin column). Protein concentration and degree of labeling (DOL) were determined by measuring the absorbance of the FAMprotein conjugate at the protein absorbance maximum, 280 $\mathrm{nm}\left(\mathrm{A}_{280}\right)$, and the fluorophore emission maximum, $494 \mathrm{~nm}$ $\left(\mathrm{A}_{494}\right)$. Protein absorbance was corrected for the contribution of the fluorophore to $A_{280}$ by subtracting $A_{494}$ weighted by the correction factor (CF), an empirical constant of 0.17 for free FAM (from manufacturer). Protein and FAM concentrations were determined by the Beer-Lambert Law using either $\mathrm{A}_{280}$ for protein or $\mathrm{A}_{494}$ for FAM, with the corresponding extinction coefficients of $\varepsilon_{280 \mathrm{~nm}, \mathrm{HSA}}=43,824$ (M $\mathrm{cm})^{-1,49} \varepsilon_{280 \mathrm{~nm}, \mathrm{FBG}}=513,400(\mathrm{M} \mathrm{cm})^{-1,50}$ and $\varepsilon_{494 \mathrm{~nm}, \mathrm{FAM}}=$ $75,000\left(\mathrm{M} \mathrm{cm}^{-1}\right.$ (from manufacturer). DOL was then calculated as the ratio of FAM to protein molar concentrations, yielding DOLFAM-HSA $=2.773$ and DOL FAM-FBG $=0.608$.

Free FAM NHS ester remaining after purification was quantified by polyacrylamide gel electrophoresis (PAGE) run according to the Laemmli protocol ${ }^{51}$ (adapted in BioRad Mini-PROTEAN Tetra Cell manual). Briefly, purified FAM-protein conjugates were added to sodium dodecyl sulfate (SDS) reducing buffer $(2 \%$ SDS, $5 \% \beta$-mercaptoethanol, $0.066 \mathrm{M}$ Tris- $\mathrm{HCl}$ ) in a 1:2 ratio of sample to buffer. Samples were diluted such that $100 \mathrm{ng}$ of FAM-HSA, $100 \mathrm{ng}$ of FAM NHS ester, or $30 \mathrm{ng}$ of FAM-FBG (due to lower labeling reaction yield) per $20 \mu \mathrm{L}$ volume was applied per well. PAGE separation was carried out in $1 \mathrm{~mm}$ vertical mini gel format (Bio-Rad Mini-PROTEAN Tetra Cell) with a discontinuous buffer system under denaturing conditions. Gel composition was $12 \%$ acrylamide (total monomer), $0.375 \mathrm{M}$ Tris$\mathrm{HCl}, 0.1 \%$ SDS, $0.05 \%$ APS, $0.05 \%$ TEMED for the resolving gel and $12 \%$ acrylamide (total monomer), $0.125 \mathrm{M}$ Tris- $\mathrm{HCl}$, $0.1 \%$ SDS, $0.05 \%$ APS, $0.1 \%$ TEMED for the stacking gel. Electrode buffer was $25 \mathrm{mM}$ Tris, $192 \mathrm{mM}$ glycine, and 3.5 mM SDS (pH 8.3). Separation was run with $200 \mathrm{~V}$ for 35 minutes, gels were extracted, and the FAM label was visualized with a gel imager (Typhoon FLA 9500, $473 \mathrm{~nm}$ laser, General Electric) (Fig. S3). The FAM-protein conjugate is the 
higher band (approximately $66 \mathrm{kDa}$ for FAM-HSA, 52-95 $\mathrm{kDa}$ for FAM-FBG) and the free, lighter molecular weight FAM NHS ester is the lower band (approximately 0.475 $\mathrm{kDa}$ ). FAM fluorescence intensity was quantified with ImageJ (Table S1).

\subsection{Visible fluorescence measurements}

Equal volumes of (GT) ${ }_{6}$-Cy5-SWCNT and FAM-tagged protein at $2 X$ working concentration were added to a 96well PCR plate (Bio-Rad) to a total volume of $50 \mu \mathrm{L}$. The plate was sealed using an optically transparent adhesive seal (Bio-Rad) and briefly spun down on a benchtop centrifuge. Fluorescence time series readings were taken using a Bio-Rad CFX96 Real Time qPCR System, scanning all manufacturer set color channels (FAM, HEX, Texas Red, Cy5, Quasar 705) every $30 \mathrm{~s}$ at $22.5^{\circ} \mathrm{C}$ (lid heating off). Fluorescence time series were analyzed without default background correction. Note that concentration ranges of FAM-HSA (5-60 $\mu \mathrm{g} / \mathrm{mL})$ and FAM-FBG (40-160 $\mu \mathrm{g} / \mathrm{mL})$ were chosen to be in the linear fluorescence regime of the qPCR.

\subsection{Near-infrared fluorescence measurements}

Fluorescence spectra were collected with an inverted Zeiss microscope (20x objective, Axio Observer.D1) containing a custom filter cube set (800 nm SP FESH0800, 900 nm LP dichroic DMLP900R, 900 nm LP FELH900, ThorLabs) coupled to a Princeton Instruments spectrometer (SCT 320) and liquid nitrogen cooled Princeton Instruments InGaAs detector (PyLoN-IR 1024/1.7). Fluorescence measurements were done with a beam-expanded $721 \mathrm{~nm}$ laser (10$500 \mathrm{~mW}$, OptoEngine LLC) excitation light source and 800 $1400 \mathrm{~nm}$ emission wavelength range. Solution-phase measurements were acquired in a 384 well-plate format ( $1 \mathrm{~s}$ exposure time, $1 \mathrm{~mW}$ laser power). Protein solutions (final concentration $40 \mu \mathrm{g} / \mathrm{mL}$ ) or PBS control were incubated with (GT) ${ }_{6}$-SWCNTs (final concentration $5 \mu \mathrm{g} / \mathrm{mL}$ in $0.1 \mathrm{M}$ PBS). For each time point, an aliquot of these incubation solutions was added to a well ( $40 \mu \mathrm{L}$ total volume) and an initial fluorescence spectrum was acquired. $10 \mu \mathrm{L}$ of dopamine was added to a final concentration of $200 \mu \mathrm{M}$ prior to the second fluorescence acquisition. Fluorescence fold change was measured by taking the ratio of fluorescence intensities at $1200 \mathrm{~nm}$ between post- and pre-addition of dopamine spectra.

Similarly, surfactant-induced solvatochromism was performed by collecting nIR fluorescence spectra pre- and 1minute post-addition of $0.5 \%(\mathrm{w} / \mathrm{v})$ SDBS. Fluorescence fold change was defined as the ratio of integrated fluorescence intensity (800 to $1400 \mathrm{~nm}$ ) between post- and preaddition of SDBS. Wavelength shift was measured relative to the wavelength of the $(7,6)$ SWCNT chirality peak emission (initially $1130 \mathrm{~nm}$ ) post-SDBS.

\subsection{Kinetic model}

Corona exchange kinetics were modeled by a system of simultaneous adsorption/desorption reactions. The model assumes that both ssDNA and protein adsorb/desorb reversibly to a fixed number of vacant SWCNT surface sites
(Equations 1 and 2). Note that all modeling was done on a mass basis. This is in agreement with the general use of volume fractions in polymer thermodynamics. ${ }^{52}$ Here, we add the additional assumption that the biomolecules are of similar density. Modeling on a mass basis accounts for the widely varying molecular sizes between the two types of protein (HSA, $66.5 \mathrm{kDa}$, globular vs. FBG, $340 \mathrm{kDa}$, long) and ssDNA ((GT)6, $3.7 \mathrm{kDa})$. The time-dependent differential equations governing ssDNA desorption and protein adsorption are as follows:

$$
\begin{array}{cr}
\frac{d}{d t}[D]=-k_{1}[*]_{T}[D]+\left(k_{1}[D]+k_{2}\right)\left([D]_{T}-[D]\right)+ \\
k_{1}[D]\left([P]_{T}-[P]\right) & (\text { Eq. S1) } \\
\frac{d}{d t}[P]=-k_{3}[*]_{T}[P]+\left(k_{3}[P]+k_{4}\right)\left([P]_{T}-[P]\right)+ \\
k_{3}[P]\left([D]_{T}-[D]\right)
\end{array}
$$

A least-squares regression was used to fit the model to fluorescence data and iterate model parameters. MATLAB 2019A's ode15s solver was implemented to solve Equations S1 and S2 for free protein and DNA concentration curves given fit rate constants $\mathrm{k}_{1}, \mathrm{k}_{2}, \mathrm{k}_{3}, \mathrm{k}_{4}$, and the total concentration of open sites, $\left[{ }^{*}\right]_{\mathrm{T}}$. Relative error between the model fit and experimental data was calculated and averaged over all data points to yield mean relative error (MRE). Sensitivity analysis on initial conditions was performed to minimize this fit error. 48 unique combinations of rate parameter initial conditions were analyzed as inputs to the nonlinear least-squares solver (lsqcurvefit) in our MATLAB model. The optimal set of initial conditions for each protein was chosen as that which yielded a low MRE between fit and experimental data and a low standard error among fit parameters for each of the four protein concentrations. Each rate parameter was individually fit to each experiment, yielding 20 total fit parameters from each initial condition (Table S2). Final ssDNA and protein fit MRE were all < 5\% (Table S2). Optimized initial conditions and resultant rate parameters for HSA and FBG are reported in Table S3.

Two alternative models were also attempted: in Model 2, protein was able to bind to surface-adsorbed ssDNA and in Model 3, protein was able to bind to surface-adsorbed protein. However, these models both produced significantly higher error in fits. Model 2 addressed the possibility of protein binding on top of ssDNA bound directly to the SWCNT. For FBG experiments fit with Model 2, most fits overestimated FBG adsorption and many fits displayed incorrect concavity for the ssDNA desorption. For HSA experiments fit with Model 2, the protein data was generally fit well but the ssDNA fits exhibited either a maximum or produced linear fits. Model 3 addressed the possibility of protein binding on top of protein bound directly to the SWCNT. For FBG experiments, Model 3 overestimated both protein adsorption and ssDNA desorption. For HSA experiments, Model 3 generally fit the protein data well, yet did not capture ssDNA dynamics as a function of concentration. Although the higher errors associated with Model 2 and 3 do not rule out these nanoscale mechanistic possibilities, the simple model of independent binding does overall fit the data much more 
bioRxiv preprint doi: https://doi.org/10.1101/761296; this version posted September 10, 2019. The copyright holder for this preprint (which was not certified by peer review) is the author/funder. All rights reserved. No reuse allowed without permission.

closely between both protein and ssDNA curves within the same experiment, as well as binding dynamics as a function of varying concentration.

\section{ASSOCIATED CONTENT}

\section{Supporting Information}

Figures S1-S7 and Tables S1-S3 included with further experimental validation.

\section{AUTHOR INFORMATION}

\section{Corresponding Author}

*Markita P. Landry, e-mail: landry@berkeley.edu

\section{Author Contributions}

$\$$ These authors contributed equally.

\section{ACKNOWLEDGMENT}

We acknowledge support of an NIH NIDA CEBRA award \# R21DA044010 (to M.P.L.), a Burroughs Wellcome Fund Career Award at the Scientific Interface (CASI) (to M.P.L.), the Simons Foundation (to M.P.L.), a Stanley Fahn PDF Junior Faculty Grant with Award \# PF-JFA-1760 (to M.P.L.), a Beckman Foundation Young Investigator Award (to M.P.L.), and a DARPA Young Investigator Award (to M.P.L.). M.P.L. is a Chan Zuckerberg Biohub investigator. R.L.P., D.Y., and W.C. all acknowledge the support of NSF Graduate Research Fellowships.

\section{ABBREVIATIONS}

ssDNA, single-stranded DNA; (GT), guanine-thymine; SWCNT, single-walled carbon nanotube; HSA, human serum albumin; FBG, fibrinogen; PBS, phosphate-buffered saline; nIR, near-infrared; SDBS, sodium dodecylbenzenesulfonate

\section{REFERENCES}

(1) Zhang, J.; Landry, M. P.; Barone, P. W.; Kim, J.-H.; Lin, S.; Ulissi, Z. W.; Lin, D.; Mu, B.; Boghossian, A. A.; Hilmer, A. J.; et al. Molecular Recognition Using Corona Phase Complexes Made of Synthetic Polymers Adsorbed on Carbon Nanotubes. Nature Nanotechnology 2013, 8 (12), 959-968. https://doi.org/10.1038/nnano.2013.236.

(2) Liu, Z.; Tabakman, S.; Welsher, K.; Dai, H. Carbon Nanotubes in Biology and Medicine: In Vitro and in Vivo Detection, Imaging and Drug Delivery. Nano Res. 2009, 2 (2), 85-120. https://doi.org/10.1007/s12274-0099009-8.

(3) Demirer, G. S.; Zhang, H.; Matos, J. L.; Goh, N. S.; Cunningham, F. J.; Sung, Y.; Chang, R.; Aditham, A. J.; Chio, L.; Cho, M.-J.; et al. High Aspect Ratio Nanomaterials Enable Delivery of Functional Genetic Material without DNA Integration in Mature Plants. Nature Nanotechnology 2019, 1. https://doi.org/10.1038/s41565-0190382-5.

(4) Zheng, M.; Jagota, A.; Semke, E. D.; Diner, B. A.; Mclean, R. S.; Lustig, S. R.; Richardson, R. E.; Tassi, N. G. DNAAssisted Dispersion and Separation of Carbon Nanotubes. Nature Materials 2003, 2 (5), 338-342. https://doi.org/10.1038/nmat877.
(5) Marchesan, S.; Prato, M. Under the Lens: Carbon Nanotube and Protein Interaction at the Nanoscale. Chem. Commun. 2015, 51 (21), 4347-4359. https://doi.org/10.1039/C4CC09173F.

(6) Cedervall, T.; Lynch, I.; Lindman, S.; Bergg \a ard, T.; Thulin, E.; Nilsson, H.; Dawson, K. A.; Linse, S. Understanding the Nanoparticle-Protein Corona Using Methods to Quantify Exchange Rates and Affinities of Proteins for Nanoparticles. Proceedings of the National Academy of Sciences 2007, 104 (7), 2050-2055.

(7) Nel, A. E.; Mädler, L.; Velegol, D.; Xia, T.; Hoek, E. M. V.; Somasundaran, P.; Klaessig, F.; Castranova, V.; Thompson, M. Understanding Biophysicochemical Interactions at the Nano-Bio Interface. Nature Materials $\begin{array}{lrll}\text { 2009, } & 8 & \text { (7), } & \text { 543-557. }\end{array}$ https://doi.org/10.1038/nmat2442.

Gravely, M.; Safaee, M. M.; Roxbury, D. Biomolecular Functionalization of a Nanomaterial to Control Stability and Retention within Live Cells. Nano Lett. 2019. https://doi.org/10.1021/acs.nanolett.9b02267.

Bisker, G.; Bakh, N. A.; Lee, M. A.; Ahn, J.; Park, M.; O'Connell, E. B.; Iverson, N. M.; Strano, M. S. Insulin Detection Using a Corona Phase Molecular Recognition Site on Single-Walled Carbon Nanotubes. ACS Sens. 2018, 3 (2), 367-377. https://doi.org/10.1021/acssensors.7b00788.

(10) Beyene, A. G.; McFarlane, I. R.; Pinals, R. L.; Landry, M. P. Stochastic Simulation of Dopamine Neuromodulation for Implementation of Fluorescent Neurochemical Probes in the Striatal Extracellular Space. ACS Chem. Neurosci. 2017, 8 (10), 2275-2289. https://doi.org/10.1021/acschemneuro.7b00193.

(11) Beyene, A.; Alizadehmojarad, A. A.; Dorlhiac, G.; Goh, N.; Streets, A.; Král, P.; Vukovic, L.; Landry, M. P. Ultralarge Modulation of Fluorescence by Neuromodulators in Carbon Nanotubes Functionalized with Self-Assembled Oligonucleotide Rings. Nano Lett. 2018. https://doi.org/10.1021/acs.nanolett.8b02937.

(12) Beyene, A. G.; Delevich, K.; Bonis-O'Donnell, J. T. D.; Piekarski, D. J.; Lin, W. C.; Thomas, A. W.; Yang, S. J.; Kosillo, P.; Yang, D.; Prounis, G. S.; et al. Imaging Striatal Dopamine Release Using a Nongenetically Encoded near Infrared Fluorescent Catecholamine Nanosensor. Science Advances 2019, 5 (7), eaaw3108. https://doi.org/10.1126/sciadv.aaw3108.

(13) Dijt, J. C.; Cohen Stuart, M. A.; Fleer, G. J. Competitive Adsorption Kinetics of Polymers Differing in Length Only. Macromolecules 1994, 27 (12), 3219-3228. https://doi.org/10.1021/ma00090a015.

(14) Landry, M. P.; Vuković, L.; Kruss, S.; Bisker, G.; Landry, A. M.; Islam, S.; Jain, R.; Schulten, K.; Strano, M. S. Comparative Dynamics and Sequence Dependence of DNA and RNA Binding to Single Walled Carbon Nanotubes. The Journal of Physical Chemistry C 2015, 119 (18), 10048-10058. https://doi.org/10.1021/jp511448e.

(15) Silvera-Batista, C. A.; Wang, R. K.; Weinberg, P.; Ziegler, K. J. Solvatochromic Shifts of Single-Walled Carbon Nanotubes in Nonpolar Microenvironments. Phys. Chem. Chem. Phys. 2010, 12 (26), 6990-6998. https://doi.org/10.1039/B927053A.

(16) Larsen, B. A.; Deria, P.; Holt, J. M.; Stanton, I. N.; Heben, M. J.; Therien, M. J.; Blackburn, J. L. Effect of Solvent Polarity and Electrophilicity on Quantum Yields and Solvatochromic Shifts of Single-Walled Carbon Nanotube 
bioRxiv preprint doi: https://doi.org/10.1101/761296; this version posted September 10, 2019. The copyright holder for this preprint (which was not certified by peer review) is the author/funder. All rights reserved. No reuse allowed without permission.

Photoluminescence. J. Am. Chem. Soc. 2012, 134 (30), 12485-12491. https://doi.org/10.1021/ja2114618.

(17) Choi, J. H.; Strano, M. S. Solvatochromism in SingleWalled Carbon Nanotubes. Appl. Phys. Lett. 2007, 90 (22), 223114. https://doi.org/10.1063/1.2745228.

(18) Oh, H.; Sim, J.; Ju, S.-Y. Binding Affinities and Thermodynamics of Noncovalent Functionalization of Carbon Nanotubes with Surfactants. Langmuir 2013, 29 (35), 11154-11162. https://doi.org/10.1021/la4022933.

(19) Harvey, J. D.; Jena, P. V.; Baker, H. A.; Zerze, G. H.; Williams, R. M.; Galassi, T. V.; Roxbury, D.; Mittal, J.; Heller, D. A. A Carbon Nanotube Reporter of MicroRNA Hybridization Events in Vivo. Nature Biomedical Engineering 2017, 1 (4), 0041. https://doi.org/10.1038/s41551-017-0041.

(20) Shankar, A.; Mittal, J.; Jagota, A. Binding between DNA and Carbon Nanotubes Strongly Depends upon Sequence and Chirality. Langmuir 2014, 30 (11), 31763183. https://doi.org/10.1021/la500013c.

(21) Roxbury, D.; Tu, X.; Zheng, M.; Jagota, A. Recognition Ability of DNA for Carbon Nanotubes Correlates with Their Binding Affinity. Langmuir 2011, 27 (13), 82828293. https://doi.org/10.1021/la2007793.

(22) Jena, P. V.; Safaee, M. M.; Heller, D. A.; Roxbury, D. DNACarbon Nanotube Complexation Affinity and Photoluminescence Modulation Are Independent. ACS Applied Materials \& Interfaces 2017, 9 (25), 21397-21405. https://doi.org/10.1021/acsami.7b05678.

(23) Zheng, Y.; Bachilo, S. M.; Weisman, R. B. Enantiomers of Single-Wall Carbon Nanotubes Show Distinct Coating Displacement Kinetics. J. Phys. Chem. Lett. 2018, 37933797. https://doi.org/10.1021/acs.jpclett.8b01683.

(24) Jeng, E. S.; Moll, A. E.; Roy, A. C.; Gastala, J. B.; Strano, M. S. Detection of DNA Hybridization Using the Near-Infrared Band-Gap Fluorescence of Single-Walled Carbon Nanotubes. Nano Lett. 2006, 6 (3), 371-375. https://doi.org/10.1021/nl051829k.

(25) Barone, P. W.; Baik, S.; Heller, D. A.; Strano, M. S. NearInfrared Optical Sensors Based on Single-Walled Carbon Nanotubes. Nature Materials 2005, 4 (1), 86-92. https://doi.org/10.1038/nmat1276.

(26) Zhu, Z.; Yang, R.; You, M.; Zhang, X.; Wu, Y.; Tan, W. Single-Walled Carbon Nanotube as an Effective Quencher. Anal Bioanal Chem 2010, 396 (1), 73-83. https://doi.org/10.1007/s00216-009-3192-z.

(27) Umemura, K.; Sato, S.; Bustamante, G.; Ye, J. Y. Using a Fluorescence Quenching Method to Detect DNA Adsorption onto Single-Walled Carbon Nanotube Surfaces. Colloids and Surfaces B: Biointerfaces 2017, 160, 201-206.

https://doi.org/10.1016/j.colsurfb.2017.09.029.

(28) Anderson, N. L.; Anderson, N. G. The Human Plasma Proteome: History, Character, and Diagnostic Prospects. Molecular \& Cellular Proteomics 2002, 1 (11), 845-867. https://doi.org/10.1074/mcp.R200007MCP200.

(29) Plasma Fibrinogen. Ann Clin Biochem 2004, 41 (6), 430-440.

https://doi.org/10.1258/0004563042466884.

(30) Foroozandeh, P.; Aziz, A. A. Merging Worlds of Nanomaterials and Biological Environment: Factors Governing Protein Corona Formation on Nanoparticles and Its Biological Consequences. Nanoscale Research Letters
2015, 10 (1), 221. https://doi.org/10.1186/s11671015-0922-3.

(31) Monopoli, M. P.; Walczyk, D.; Campbell, A.; Elia, G.; Lynch, I.; Baldelli Bombelli, F.; Dawson, K. A. Physical-Chemical Aspects of Protein Corona: Relevance to in Vitro and in Vivo Biological Impacts of Nanoparticles. J. Am. Chem. Soc. 2011, 133 (8), 2525-2534. https://doi.org/10.1021/ja107583h.

(32) Lundqvist, M.; Stigler, J.; Elia, G.; Lynch, I.; Cedervall, T.; Dawson, K. A. Nanoparticle Size and Surface Properties Determine the Protein Corona with Possible Implications for Biological Impacts. Proceedings of the $\mathrm{Na}$ tional Academy of Sciences 2008, 105 (38), 1426514270.

(33) Beyene, A. G.; Delevich, K.; ODonnell, J. T. D. B.; Piekarski, D. J.; Lin, W. C.; Thomas, A. W.; Yang, S. J.; Kosillo, P.; Yang, D.; Wilbrecht, L.; et al. Imaging Striatal Dopamine Release Using a Non-Genetically Encoded NearInfrared Fluorescent Catecholamine Nanosensor. bioRxiv 2018, 356543. https://doi.org/10.1101/356543.

(34) Lu, N.; Sui, Y.; Tian, R.; Peng, Y.-Y. Adsorption of Plasma Proteins on Single-Walled Carbon Nanotubes Reduced Cytotoxicity and Modulated Neutrophil Activation. Chem. Res. Toxicol. 2018, 31 (10), 1061-1068. https://doi.org/10.1021/acs.chemrestox.8b00141.

(35) Salvador-Morales, C.; Flahaut, E.; Sim, E.; Sloan, J.; H. Green, M. L.; Sim, R. B. Complement Activation and Protein Adsorption by Carbon Nanotubes. Molecular Immunology 2006, 43 (3), 193-201. https://doi.org/10.1016/j.molimm.2005.02.006.

(36) Ge, C.; Du, J.; Zhao, L.; Wang, L.; Liu, Y.; Li, D.; Yang, Y.; Zhou, R.; Zhao, Y.; Chai, Z.; et al. Binding of Blood Proteins to Carbon Nanotubes Reduces Cytotoxicity. Proceedings of the National Academy of Sciences 2011, 108 (41), 16968-16973.

(37) Wertz, C. F.; Santore, M. M. Adsorption and Relaxation Kinetics of Albumin and Fibrinogen on Hydrophobic Surfaces: Single-Species and Competitive Behavior.

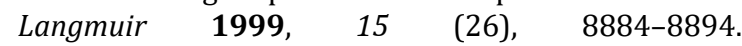
https://doi.org/10.1021/la990089q.

(38) Mubarekyan, E.; Santore, M. M. Adsorption and Exchange Dynamics in Aging Hydroxyethylcellulose Layers on Silica. Journal of Colloid and Interface Science 2000, $227 \quad$ (2), 334-344. https://doi.org/10.1006/jcis.2000.6899.

(39) Wertz, C. F.; Santore, M. M. Effect of Surface Hydrophobicity on Adsorption and Relaxation Kinetics of Albumin and Fibrinogen: Single-Species and Competitive Behavior. Langmuir 2001, 17 (10), 3006-3016. https://doi.org/10.1021/la0017781.

(40) Jungbauer, L. M.; Yu, C.; Laxton, K. J.; LaDu, M. J. Preparation of Fluorescently-Labeled Amyloid-Beta Peptide Assemblies: The Effect of Fluorophore Conjugation on Structure and Function. Journal of Molecular Recognition 2009, 22 (5), 403-413. https://doi.org/10.1002/jmr.948.

(41) Brunecker, F. K.; Schöppler, F.; Hertel, T. Interaction of Polymers with Single-Wall Carbon Nanotubes. J. Phys. Chem. C 2016, 120 (18), 10094-10103. https://doi.org/10.1021/acs.jpcc.6b02198.

(42) Dijt, J. C.; Cohen Stuart, M. A.; Fleer, G. J. Surface Exchange Kinetics of Chemically Different Polymers. Macromolecules 1994, 27 (12), 3229-3237. https://doi.org/10.1021/ma00090a016. 
(43) De Paoli, S. H.; Diduch, L. L.; Tegegn, T. Z.; Orecna, M.; Strader, M. B.; Karnaukhova, E.; Bonevich, J. E.; Holada, K.; Simak, J. The Effect of Protein Corona Composition on the Interaction of Carbon Nanotubes with Human Blood Platelets. Biomaterials 2014, 35 (24), 61826194. https://doi.org/10.1016/j.biomaterials.2014.04.067.

(44) Tenzer, S.; Docter, D.; Kuharev, J.; Musyanovych, A.; Fetz, V.; Hecht, R.; Schlenk, F.; Fischer, D.; Kiouptsi, K.; Reinhardt, C.; et al. Rapid Formation of Plasma Protein Corona Critically Affects Nanoparticle Pathophysiology. Nat Nanotechnol 2013, 8 (10), 772-781. https://doi.org/10.1038/nnano.2013.181.

(45) Cell Membrane Proteins Modulate the Carbon Nanotube Optical Bandgap via Surface Charge Accumulation I ACS Nano https://pubs.acs.org/doi/abs/10.1021/acsnano.5b05 438 (accessed Jun 24, 2019).

(46) Moore, V. C.; Strano, M. S.; Haroz, E. H.; Hauge, R. H.; Smalley, R. E.; Schmidt, J.; Talmon, Y. Individually Suspended Single-Walled Carbon Nanotubes in Various Surfactants. Nano Lett. 2003, 3 (10), 1379-1382. https://doi.org/10.1021/nl034524j.

(47) Okazaki, T.; Saito, T.; Matsuura, K.; Ohshima, S.; Yumura, M.; Iijima, S. Photoluminescence Mapping of "As-
Grown" Single-Walled Carbon Nanotubes: A Comparison with Micelle-Encapsulated Nanotube Solutions. Nano Lett. 2005, 5 (12), 2618-2623. https://doi.org/10.1021/nl051888y.

(48) Nißler, R.; Mann, F. A.; Chaturvedi, P.; Horlebein, J.; Meyer, D.; Vuković, L.; Kruss, S. Quantification of the Number of Adsorbed DNA Molecules on Single-Walled Carbon Nanotubes. J. Phys. Chem. C 2019, 123 (8), 4837-4847.

https://doi.org/10.1021/acs.jpcc.8b11058.

(49) Gill, S. C.; von Hippel, P. H. Calculation of Protein Extinction Coefficients from Amino Acid Sequence Data. Analytical Biochemistry 1989, 182 (2), 319-326. https://doi.org/10.1016/0003-2697(89)90602-7.

(50) Marder, V. J.; Shulman, N. R.; Carroll, W. R. High Molecular Weight Derivatives of Human Fibrinogen Produced by Plasmin I. PHYSICOCHEMICAL AND IMMUNOLOGICAL CHARACTERIZATION. J. Biol. Chem. 1969, 244 (8), 2111-2119.

(51) Laemmli, U. K. Cleavage of Structural Proteins during the Assembly of the Head of Bacteriophage T4. Nature $\begin{array}{lll}\text { 1970, } 227 & \text { (5259), 680-685. }\end{array}$ https://doi.org/10.1038/227680a0.

(52) Flory, P. J. Principles of Polymer Chemistry; Cornell University Press, 1953. 